Understanding Generation Alpha

Amrit Kumar Jha1,2

amrit@iitkgp.ac.in

IC. M. College, Lalit Narayan Mithila University, Darbhanga, Bihar, 846004, India

2Indian Institute of Technology Kharagpur, Kharagpur, West Bengal, 721302, India

\begin{abstract}
Much has been studied and known about the twentieth-century generations with emphasis on the Millennials and Generation $\mathrm{Z}$ related to their personality traits, value systems, aspirations, and cultural fit at organization and societal level. Their successor, the first true generation of the twenty-first century, namely the Generation Alpha, had already made their mark in the consumerism and technology-driven world. Born in and after 2010, the eldest Generation Alpha is still in their school-years and had already influenced the trend of marketing, technology, and priorities of their millennials parent. There is a dearth of study exploring the different facets of Generation Alpha and to this end, the present paper attempts to unravel, understand, and contextualize Generation Alpha within the ecology of the twenty-first century world. Considering the present and the future to reckon, certain psychological traits of Generation Alpha along with their problems and vulnerabilities have been discussed. The paper envisages a promising future for Generation Alpha, but with caveats, requiring timely interventions.
\end{abstract}

Keywords: Generation, Generation Alpha, Technology, Millennials, Generation Z. 


\section{Understanding Generation Alpha}

\section{Introduction}

Life in the present 21 st-century world reflect the years of combined hardships, patience, vision, and labor of relentless human endeavors to achieve what they are comforting themselves today with. Traveling and remembering the years of dark age to renaissance to the era of enlightenment of modern age and now the post-modernistic world, if one could live through them, they would underscore the saliency and value of the present day scientific and technological advancements; standard and comfort of life and information abundance; dedicated to the service of mankind. Referred to as the age of Internet and Communication Technology (ICT) driven knowledge, the 21 st-century has presented world an unprecedented reality that was a distant dream in the past. The rapid advancements and use of ICT devices (smartphones, laptops, smartwatches, play stations), 24*7*365 electricity, evolution from an agrarian society to the service-driven economy, borderless world, dual-career families, deskjobs, and over-involvement in social media, among others characterizes the present advanced world.

In this backdrop, with the evolving devices and machines, mankind seems to catch up by evolving from generation to generation. They are the ones responsible for being creators, consumers, and decomposers of these machines. Generational studies have documented human beings of the modern twentieth-century era from their anchoring point as GIs generation (abbreviated as either General Issue or Government Issue). The latest entry in the list and the focal point of the paper is the first generation of $21_{\text {st }}$ century referred as Generation Alpha (Gen Alpha) (Howe \& Strauss, 1990; McCrindle, 2008).

\subsection{Generation}

Ryder (1965) posits generation as demographic metabolism, representing generation as active social change which describe a recurrent and steady pattern of coming and going in 
a given historical and social events (Table 1). Manheim (1952) and Ryder (1965) observed that a generation reflects a cohort of individuals who have experienced and responded to the same historical events inherent within the same time period and location.

Table 1: Timeline of twentieth century generations

\begin{tabular}{lll}
\hline Sl. No & Generations & Timeline \\
\hline 1 & GIs & $1901-1924$ \\
2 & Silents & $1925-1945$ \\
3 & Baby Boomers & $1946-1964$ \\
4 & Generation X & $1965-1980$ \\
5 & Generation Y/Millennials & $1981-1996$ \\
6 & Generation Z/iGens & $1997-2010$ \\
7 & Generation Alpha* & $2010-2025$ \\
\hline
\end{tabular}

Note: Based on works of Strauss and Howe (1991); Howe and Strauss (2000); McCrindle, (2008); Pew Research Centre (2019). *Generation Alpha = Twenty-first century

\section{Generation Alpha}

Coined by a generational researcher, Mark McCrindle (2008), Gen Alpha is named after first letter of Greek alphabet, Alpha. Their immediate predecessors, Generation Z mark the end of Latin alphabets in the series of naming generations, paving way for the Gen Alpha to emerge.

Born to their millennials parent, Gen Alpha are considered to be born between 2010 and 2025. Their birth year (2010) coincides with the launch of iPad and Instagram presently world's most preferred brand and social media application, respectively. They are born in an era of rapid advanced technologies operating $24 * 7 * 365$ globally. Technology means world to them. From entertainment, gaming, connecting to peers, and even education in the wake of COVID-19 pandemic, their life revolves around technology (Jha \& Arora, 2020). Recently, it was found that by the age of two, Gen Alpha master touchscreen and easily navigate through various apps on smartphones, which their predecessors took years 
(Turk, 2017), earning them the labels of screenagers, digital natives, and connected or wired generation (Tootell et al., 2014).

\subsection{The Ecology of Generation Alpha}

For understanding the psychological traits of Gen Alpha, it is imperative to understand their ecology of birth which will give a holistic sense of their generation locality. Gen Alpha is in a real sense the first millennium generation compared to their elders. Life in the millennium world is quite different to that of pre-millennium age. From lifestyle; pattern of relationships; nature of jobs; gender roles; both the personal and professional life have changed drastically. Tele-work, flexi-time, work from home or remote working, working in shifts, and rise in dual-career families have blurred the boundaries separating personal and professional life for millennials, impacting Gen Alpha. Compared to their elders, Gen Alpha are living in a different technology driven-reality, which may wreak havoc for their future life. Psychoanalysts and developmental psychologists with the likes of Bowlby, Freud, and Piaget have underscore the prominence of early days of life for a secure attachment, cognitive and social development leading to a strong, stable, and adaptive personality in future. Freud (1923) stresses upon the indispensable role of childhood and parenting for a stronger ego to emerge, free from anxieties, vulnerabilities, and conflicts, encapsulated in 'child is the father of man', axiom.

To understand the ecology of Gen Alpha, observing cultural factors will provide a better understanding of their immediate context. In Australia, primarily an individualistic nation, McCrinddle and Wolfinger (2010) observed an unparalleled reality before Gen Alpha in terms of-(a) numbers of women and mothers being employed, (b) number of babies in paid or foster care, (c) parents being older, (d) families being smaller, and (e) lower household population. Given their parents, the millennials, have spent more or less similar lives in this globalized tech-world, such observations may also encompass this new 
generation in collectivistic countries too like India, where preferences toward individualism is growing. In India, traditionally, family ethos, cultural norms, high parental power distance, and interpersonal-self dominates. Over the years, introduction of Liberalization, Privatization, and Globalization during the early nineties and later the IT revolution has transformed India socially, culturally, and financially. Gradually, millennials move toward cosmopolitan cities in search of better job opportunities and standard of life. From this disequilibrium, emerged fragmented societies, paving way for nuclear families; dual-career jobs; proportionate rise in the standard of living; need for materialistic pleasures, furthered by the advent of consumerism and ICT.

In this backdrop, came the Gen Alpha, whose birth years nearly coincide with the global financial crisis of 2008. The worst economic disaster post the Great Depression of 1929, sending their millennials parent into a zone of economic despair. Arriving as a ray of hope and shine, Gen Alpha ensured the continuity and stability in their parents' life.

\subsection{Generation Alpha and Vulnerabilities}

Mannheim (1952) suggested the term 'generational location' for the problem subjective to every generation and unique to every cohort belonging to a specific historical period of time. Gen Alpha bears no exception. Compared to their predecessors, they are born in a time when the world was recovering from the global financial crisis, new avenues of digital technologies and social media were up to penetrate the whole world, change in family structures, never-ending climate change debate, among others with the recent COVID-19 pandemic in the list.

For Gen Alpha, vulnerabilities emerging out of digital technologies are second to none. From psychological and physiological impact including cognition (Wilmer et al., 2017), sleep (Jha et al., 2019), and impaired social and emotional well-being (Augner \& Hacker, 2012) to cyber threats and addiction, the list is ever growing. 
Gen Alpha life started connecting more with Alexa or Siri (voice box assistant of Amazon and Apple) than with their parents or friends. More than enjoying the outdoor activities or real life play, they hop upon mobile games like PUBG, Xbox, and Pokemon, within their comfort zone inside home. Such has been the widespread use of online gaming that American Psychiatric Association and World Health Organization have classified them as disorders, namely Internet Gaming Disorder and Gaming Disorder, in DSM-5 and ICD-11, respectively (APA, 2013; WHO, 2016). In one of our study, we found that an adolescent spent an average two hours on mobile gaming with sheer consequences on anger management and socialization, leading to loneliness and aggressiveness upon withdrawal (Arora \& Jha, 2020).

Physiologically and psychologically, changes in brain plasticity (or neural wirings), cognition, sleep disturbances, and obesity, constitutes the future problematic trend for Gen Alpha. Neuronal changes due to games and internet use in children are uniquely sensitive to neural plasticity. It delays the development of microstructures in the cortical brain regions and reduction in brain tissue density, leading to deficits in cognition (Takeuchi, 2016). Sleep carries a major survival value for mankind, but, marred with casual attitude toward sleep followed by technology use at night (Jha at el., 2019). The time meant for sleep is being trade-off with technology use at night-time by texting, chatting, playing games, and watching movies. Using such sleep eroding-devices leads to more screen time, further elongating the exposure to blue-light emitting diodes, leading to less production of melatonin hormone (or sleep producing hormone) and disrupting sleep-wake cycle (Figueiro \& Overington, 2016).

In the opening line of a UNICEF report on Children in Digital World, Keeley (2017) alarmingly observed the growing access and easiness of bullies, sex offenders, and traffickers in targeting their prey, here children, while staying anonymous. With the growing technology, crimes have become digital in nature too. The report categorizes three types of 
digital risks - (i) content, when a child sees any unwelcome and inappropriate content like pornographic and violent images or any hate-speech or racist material; (ii) contact, when a child comes in contact with someone seeking inappropriate behavior; and (iii) conduct, when a child does something risky.

Cyberbullying, a willful and repeated harm inflicted through the use of computers, cell phones, and other electronic devices (Hinduja \& Patchin, 2014), online child sexual abuse, and self-generated sexually explicit material has become quite common in the young generation. Nearly $53 \%$ of the sexual content and conduct victims are children less than ten years old (Internet Watch Foundation, 2018). Globally, one out of six parents admit their children experienced cyberbullying and one in six knowing a cyberbullied child (Ipsos, 2018).

In a recent survey, it was found that on average a child spent approximately 7-8 hours on mobile with the maximum time devoted to the internet, social media, gaming, and texting (Twenge, 2017). They have been lured to believe that every problem has solution courtesy technology and is available round the clock, much more than the availability of their caregivers. Technology has overpowered humans, impairing social and emotional skills, affecting relationships, which will become fatal as Gen Alpha grows up. Their immediate predecessors, Generation Z, was found to be the most vulnerable age group for suicide in the most youthful nation of the world, India (Patel et al., 2012; UNFPA, 2014). WHO (2014) further cautioned that suicide accounts for the second most leading cause in youths. Such worrying trend of their elders, who were either unknown to or partially exposed to the technology in their initial years of life, set a wrong precedent for Gen Alpha.

The change in family structure, child-rearing practices, and nature of the job in terms of helicopter parenting, small and nuclear family, dual-career family, and work from home put an excessive toll on the parents too. Theories by Bowlby (1973) and Freud (1923) had 
explicitly emphasized the importance of healthy parenting in the first two years deemed crucial for the development of a healthy attachment and relationship(s) for child in later part of life. However, the present pattern of parenting appears to be polarized with excessive love, affection, and continuous monitoring of the child on one hand and taking the help of babysitters/maids/foster caregivers during the time when they are out on the other.

\section{Nurturing the Future: The Road Ahead}

The future holds bright for Gen Alpha but with alarming and persistent caveats in future. With the exploding population, rising mental health crisis (Pitchford et al., 2019), rapid advancements in technology, viz. Artificial Intelligence, robotics, including humanoids, leading to job automation and employment crisis, the crisis might get mightier in the same proportion, COVID-19 being the fresh example.

Turkle (2011) while referring the obsession with technology, observed that mankind has reached 'the robotic moment' in their history when they are friendlier and caring to their devices more than their fellow beings. Gen Alpha, who is already battling many technological-borne issues, should be trained in the same league to detach themselves from their slavery. Jha et al. (2019) while observing the deep human-technology unification in dayto-day life, calls for a healthy and integrated approach, where both can be assimilated, for technology to stay and play the role of a powerful redeemer and not a nemesis to mankind. For a robust future of Gen Alpha, millennials parents have to play a pivotal role in their subjective, psychological, and digital well-being through timely presence and interventions. The American Association of Pediatrics (2016) has recommended amount of adequate screen-hours age wise for parents to ensure that screen time doesn't consume time slated for academic and health activities. 


\section{Suggestions for Future Research}

Future research on Gen Alpha should cater to their well-being (subjective, psychological, and digital), academic, social and emotional skills and promoting responsibility towards the society. Given their increasing affluence and intelligence, studies must include technology, value, ethicality, relationships, culture and aspirations as their underlying themes. The need is to understand them from their subjective perspective of life. Besides, studies shall also cover the family structure, both joint and nuclear family, work from home and work-life balance in conjunction with their implications on Gen Alpha.

\section{Conclusion}

Born in a rapid technological era, as compared to their parents, Gen Alpha presents exciting combination of opportunities, adventure, and explorations for the future. Driven socially, Gen Alpha share their life and thoughts publicly and knows no boundaries. They will presumably grow up being creative and unconventional. Given the zeitgeist in prospect, probably, the need for achievement, autonomy, and recognition, along with competitiveness, narcissism, ambiguity intolerance, impulsivity, attention-seeking, and risk-taking behavior will probably predominate and become salient in Gen Alpha with the passage of time. With proper parenting and guidance, the prerequisite is to install in them the right virtues and values, which are in line with the societal and traditional ethos. It is essential to inculcate in them the essence of being human, managing emotions, forming stable relationships, and a healthy-assimilation with technology in daily life. With the right mix of outdoor activities including play and forest bathing, regulated use of technology, authoritative parenting, education and instilling the 21 st-century skills namely adaptability, curiosity, critical thinking, persistence, teaming, social, and cultural awareness (World Economic Forum, 2016) will go long in shaping them to be an asset for family, society, country, and the world in future. 


\section{References}

AAP (2016), American Academy of Pediatrics Announces New Recommendations for Children's Media Use, https://www.aap.org/en-us/about-the-aap/aap-pressroom/Pages/American- Academy-of-Pediatrics-Announces-New-Recommendationsfor-Childrens-Media-Use.aspx

Arora., A. \& Jha., A., K. (2020). Understanding pattern of online gaming addiction among Indian teenagers. Our Heritage, 68(1), 13190-13100.

Augner, C., \& Hacker, G. W. (2012). Associations between problematic mobile phone use and psychological parameters in young adults. International Journal of Public Health, 57(2), 437-441.

Bowlby, J. (1973). Attachment and Loss (Vol. 2). New York: Basic Books.

Caplan, S., Williams, D., \& Yee, N. (2009). Problematic Internet use and psychosocial wellbeing among MMO players. Computers in Human Behavior, 25(6), 1312-1319.

Freud, S. (1923). The ego and the id. WW Norton \& Company.

Gottschalk, F. (2019). Impacts of technology use on children: Exploring literature on the brain, cognition and well-being. OECD Education Working Paper No. 195.

Hinduja, S., \& Patchin, J. W. (2014). Bullying beyond the schoolyard: Preventing and responding to cyberbullying. Corwin Press.

Internet Watch Foundation. (2008). Annual and charity report.

Ipsos (2018). Global Views on Cyberbullying. Retrieved from https://www.ipsos.com/en/global-views-cyberbullying

Jha, A. K., Pandey V., \& Kumari, V. (2019). What's eating up Adolescent Sleep? Evidence from Bihar. Gujarat Research Society, 21(9).

Keeley, B., \& Little, C. (2017). The State of the World Children 2017: Children in a Digital World. The United Nations Children's Fund (UNICEF). 
Mannheim, K. (1952). Essays on the sociology of knowledge. London: Routledge \& Kegan Paul Ltd.

McCrindle, M., \& Wolfinger, E. (2009). The ABC of XYZ: Understanding the global generations.

Patel, V., Ramasundarahettige, C., Vijayakumar, L., Thakur, J. S., Gajalakshmi, V., Gururaj, G., Suraweera, W., Jha, P., \& Million Death Study Collaborators. (2012). Suicide mortality in India: A nationally representative survey. The Lancet, 379(9834), 23432351.

Pitchforth, J., Fahy, K., Ford, T., Wolpert, M., Viner, R. M., \& Hargreaves, D. S. (2019). Mental health and well-being trends among children and young people in the UK, 1995-2014: Analysis of repeated cross-sectional national health surveys. Psychological Medicine, 49(8), 1275-1285.

Ryder, N. B. (1965). The cohort as a concept in the study of social change. American Sociological Review, 30, 843-861.

Takeuchi, H., Taki, Y., Hashizume, H., Asano, K., Asano, M., Sassa, Y., Yokota, S., Kotozaki, Y., Nouchi, R. \& Kawashima, R. (2016). Impact of videogame play on the brain's microstructural properties: Cross-sectional and longitudinal analyses. Molecular Psychiatry, 21(12), 1781-1789.

Tang, S., \& Patrick, M. E. (2018). Technology and interactive social media use among 8th and 10th graders in the US and associations with homework and school grades. Computers in Human Behavior, 86, 34-44.

Tootell, H., Freeman, M., \& Freeman, A. (2014). Generation alpha at the intersection of technology, play and motivation. In 2014 47th Hawaii International Conference on System Sciences (pp. 82-90). IEEE.

Turk, V. (2017). Understanding Generation Alpha. Hotwire Consulting: UK. Retrieved from 
https://www.hotwireglobal.com/generation-alpha

Turkle, S. (2011). Alone together: Why we expect more from technology and less from each other. New York: Basic Books.

Twenge, J. M. (2017). iGen: Why today's super-connected kids are growing up less rebellious, more tolerant, less happy--and completely unprepared for adulthood--and what that means for the rest of us. Simon and Schuster.

UNFPA (2014). The power of 1.8 billion adolescents, youth and the transformation of the future. The state of world population. Retrieved from https://www.unfpa.org/sites/default/files/pub-pdf/EN-SWOP14-Report_FINALweb.pdf

Wilmer, H. H., Sherman, L. E., \& Chein, J. M. (2017). Smartphones and cognition: A review of research exploring the links between mobile technology habits and cognitive functioning. Frontiers in Psychology, 8, 605.

World Health Organization (2016). ICD 11 Beta Draft. Geneva: World Health Organization. Retrieved from https://icd.who.int/browse11/lm/en\#/http://id.who.int/icd/entity/1448597234

World Economic Forum (2016). New Vision for Education: Fostering Social and Emotional Learning through Technology. Retrieved from http://www3.weforum.org/docs/WEF_New_Vision_for_Education.pdf 